\title{
Using Virtual Reality to Enhance Mineral Processing Education
}

\author{
Seher Ata*, James Tibbett \\ School of Mining Engineering, UNSW Sydney, NSW, 2052, Australia
}

\begin{abstract}
Virtual Reality (VR) is playing an increasingly important role in education. It provides the opportunity to enhance the learning experience by representing complex systems in a 3D visualisation and freeing up cognitive capacity for learning. A 3D VR simulation of a base metal concentrator has recently been developed at the University of New South Wales (UNSW) Sydney, Australia. The module provides an interactive processing plant environment where the user can walk through and explore the entire processing flowsheet and simulations in the virtual world. This paper explores the potential benefits of VR for mineral processing teaching and learning by reporting results from a study comparing traditional and virtual reality mineral processing teaching environments. The main focus is on the understanding of the mineral processing system (equipment function, layout, flowsheet) by undergraduate and postgraduate students exposed to the two styles of education.
\end{abstract}

Keywords: virtual reality, mineral processing education, mineral processing plant

\section{Introduction}

Virtual Reality (VR) is the creation of an artificial environment that is experienced through sights and sounds provided by a computer (Squelch 2001). Users immersed within this environment are able to interact with $3 \mathrm{D}$ worlds and explore their surroundings (Bell and Fogler 1996). VR has been used across a wide range of industries and applications including manufacturing (Zimmermann 2008, Jiang 2011), military (Manojlovich et al 2003), entertainment (Hsu 2011), education (Bell and Fogler 1995, 1996, 1998, Shin 2002), process design visualisation (Schofield et al 2005, Squires et al 2015) and industrial training (Squelch 2001, Mitra and Saydam 2011).

The School of Mining Engineering at the University of New South Wales (UNSW) Sydney has a number of VR modules that offer a wide range of possibilities to present and simulate complicated mine environments including underground and surface mining to make specific subjects easier to understand (Laurence and Stothard 2010, Mitra and Saydam 2011, Saydam et al 2011). These modules are integrated into an ultra-high resolution, immersive visualisation environment, also referred to as the Advanced Visualisation and Interaction Environment (AVIE), which enhances the immersive feeling in VR-scenes. Example of VR modules include evaluating the feasibility of a mining project based on factors such as the characteristics of the mineral deposit, environmental concerns and economics; and health and safety focused modules that offer learning opportunities without exposing users to unacceptable risks.

A virtual processing plant has recently been developed at UNSW Sydney where the complex flowsheet and systems involved in the mineral processing of a copper ore were explained (Ata 2017). The virtual plant is based on the Northparkes copper concentrator, which is located in central New South Wales, Australia. The concentrator has two identical parallel modules, each consisting of grinding and conventional flotation circuits. The ore is crushed and ground in a Semi-Autogenous Grinding (SAG) mill, followed by two stages of ball milling, and a flash flotation unit where high-grade fast-floating particles are removed. The flash flotation tailings are processed in rougher, scavenger, cleaner, re-cleaner and cleaner scavenger banks to produce the final copper-gold concentrate. The ore has a grade of approximately $1.4 \%$ copper and $0.4 \mathrm{~g} / \mathrm{t}$ gold. The final concentrate produced for each module assays $36 \%$ to $40 \%$ copper.

The virtual plant displays a 3D representation of the processing plant showing the interconnectivity and flow between items. Users are able to view the entire model and transition from one station to the next, as a piece of ore would. Elements within the environment are animated to showcase their function and in some cases section views are available to display the inner working of equipment to users. Panoramic photos and videos recorded in an actual plant site can also be viewed at various locations to show real-world applications of equipment in the processing plant, which helps students to identify individual unit processes forming the flowsheet and become familiar with their operation and the connection between the individual units. Relevant technical information on all the unit processes, such as dimensions, volumes and make, have also been provided along with information on the characteristics of the streams (particle size, pulp density and grade) to enhance understanding of the flowsheet's layout. Figures 1 and 2 are

* Corresponding Author: Seher Ata, Email: s.ata@unsw.edu.au, phone: +61 293857659

Copyright @ 2018 Canamaple Academia Services, http://press.camdemia.ca

DOI: 10.15273/ijge.2018.03.012 
screenshots of the module showing the grinding and flotation circuits, respectively.

The virtual concentrator is currently part of minerals processing courses taught at both undergraduate and postgraduate level at UNSW Sydney. Delivering mineral processing course material through a VR experience differs from the traditional approach of hand-out material on paper and a lecture presentation explaining the various elements in the processing flowsheet. In order to assess the potential of VR for minerals processing teaching and compare it to traditional teaching, we carried out a survey of both undergraduate and postgraduate students. This paper discusses the results of the survey.

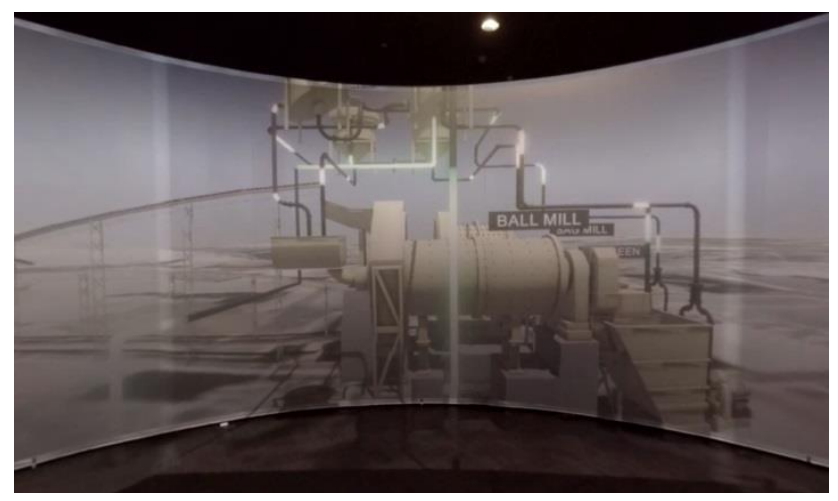

Figure 1 Screenshot of the module showing grinding circuit

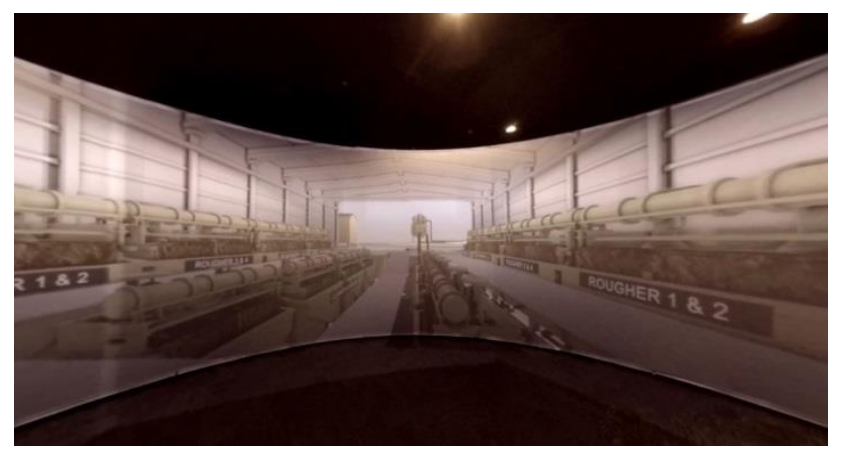

Figure 2 Screenshot of the module showing flotation circuit

\section{Methodology}

The aim of the survey was to compare two teaching delivery methods for describing a copper processing concentrator: traditional teaching and a virtual reality environment. In both modes, the students were initially provided with a basic description of a flowsheet and key information such as feed composition, particle size, reagents schemes, and flow rate of streams followed by detailed information on the individual unit processes in the flowsheet. The conventional teaching method was a lecture-based course and both delivery modes included approximately one- hour session.

Two surveys were carried out in 7 weeks apart: one with postgraduate mining engineering students and the other with first year undergraduate engineering students. The students who participated in the survey had little prior knowledge of mineral processing. In each survey, two groups of students were compared: one group was exposed to the traditional teaching method first and the other was exposed to the innovative VR experience delivery method first.

A series of questions were prepared to collect data on the effectiveness of the teaching methods. The survey had two parts. Part 1 was given to the groups of students immediately after they had been exposed to their group's initial teaching method. The groups were then swapped over to experience the other teaching method to make sure the students were educated to the same level. The students were then exposed to another survey (Part 2) to compare the two teaching methods. The questions consisted of a mix of yes/no, multiple choice, scale/rank and/or text-based responses. In Part 1 of the survey respondents were asked two multiple choice questions, three open-ended questions that allowed respondents to type their answers in their own words and five rank questions where respondents were asked to agree or disagree with a number of statements, to rate items on a scale, or to rank items in order of importance or preference. Two open-ended questions were added to Part 2 to obtain unstructured feedback. Respondents were asked the reasons for their preferred teaching method and why they found the other teaching experience less effective. The survey had Ethics approval from Human Research Ethics Committee.

\section{Results and Discussion}

Of the 52 students enrolled in the classes ( 38 UG and 14 PG) 31 students (17 UG and 14 PG) participated in the survey, giving a response rate of approximately $60 \%$.

Students were asked which teaching method they preferred, and which one gave them more understanding of the plant operation after they exposed to both delivery methods. Table 1 shows that 12 out of 14 (86\%) postgraduate and 12 out of $17(70 \%)$ undergraduate students stated they preferred VR over the traditional teaching, while. 4 out of $17(24 \%)$ undergraduates and 2 out of $14(14 \%)$ postgraduates preferred in-class teaching. Interestingly, 1 out of $17(6 \%)$ undergraduate student found the combination of both teaching modes is more effective than the in-class or VR delivery mode alone. It is also clear from the table that undergraduate students prefer the traditional lecture more than postgraduate students. The undergraduate group had a higher proportion of overseas students who may have found in-class teaching more effective, as evident from the comments presented in Table 2.

Table 1 Percentage of respondents preferring each teaching method

\begin{tabular}{lccc}
\hline & \multicolumn{3}{c}{ Teaching method } \\
\cline { 2 - 4 } & VR & Traditional & Both \\
\hline Undergraduate & $12 / 17$ & $4 / 17$ & $1 / 17$ \\
& $(70 \%)$ & $(24 \%)$ & $(6 \%)$ \\
\hline Postgraduate & $12 / 14$ & $2 / 14$ & 0 \\
& $(86 \%)$ & $(14 \%)$ & \\
\hline
\end{tabular}


Students were asked what they liked about the two modes of teaching after they were exposed to both delivery methods. Their answers are shown in Table 2. The respondents who preferred VR mentioned "visual - easy to understand", "able to see connection between the different steps" or "motivating" method, whereas respondents who preferred in-class listed "slides are better for a later recap", "more information, text visible, easier to memorise" and "prefer learning style as information is provided in words".

When students were asked to list what they disliked about their less preferred method of teaching delivery, respondents who preferred in-class mainly mentioned that "it was less effective to memorise the name of each process", and "the traditional method can get boring" while respondents who preferred VR mentioned that "it is harder to take note" and that "it [the module] is too crowded".

Students were asked to rate the teaching process on several specific dimensions (see Table 3 for the questions and the Appendix for the rating dimensions). Students' responses using the first (i.e., "extremely boring"; "extremely difficult") or last (i.e., "extremely enjoying", extremely easy) options on the seven-response choice rating scales were scored for all question items. Scores ranged from 1 to 7 for each task type where higher scores reflect a greater tendency to have a positive attitude toward the teaching methods. The results indicate that the postgraduate students were more satisfied in both VR and the traditional teaching methods than the undergraduate students. However, overall both the undergraduate and postgraduate respondents who preferred VR found the content more engaging and interesting. Both undergraduate and postgraduate students found that the material used to explain the copper processing plant was easier to understand in the VR mode than the traditional delivery method.
Table 2 Reasons given for preferring VR and traditional delivery mode

\begin{tabular}{|l|}
\hline Student responses \\
\hline Reasons for preferring VR \\
\hline (a) It was very engaging and seeing it visually make it \\
easier to understand. Absolutely love it. \\
(b) To grasp the entire process on site. \\
(c) VR was more interesting and motivating. \\
(d) Able to see the way it flows. Able to look at the \\
different steps and how it works. \\
(e) Visual learner, easier to understand. \\
(f) Difficult to visualise without VR. \\
(g) Some of the equipment and stages are unknown but \\
in VR I can identify what they are. \\
Reasons for preferring Traditional \\
(a) It is in writing form, easy for me to understand. \\
(b) Different slides for the specific apparatus. Slides are \\
better for a later recap. \\
(c) The traditional method was more in depth and had \\
more detail about the individual components of the \\
plant. \\
(d) More information, text visible, easier to write and \\
(e) Prefer learning style as information is provided in \\
words.
\end{tabular}

Table 3 Survey results from both undergraduate and postgraduate students using a 7-point rating scale (Rating dimension for each question is given in the Appendix)

\begin{tabular}{|c|c|c|c|c|c|c|c|c|c|}
\hline \multirow{3}{*}{ Questions } & \multicolumn{3}{|c|}{ Undergraduate } & \multicolumn{3}{|c|}{ Postgraduate } & \multicolumn{3}{|c|}{ Combined } \\
\hline & \multicolumn{2}{|c|}{ Ave. score } & \multirow[t]{2}{*}{ Diff. } & \multicolumn{2}{|c|}{ Ave. score } & \multirow[t]{2}{*}{ Diff. } & \multicolumn{2}{|c|}{ Ave. score } & \multirow[t]{2}{*}{ Diff. } \\
\hline & VR & $\mathbf{T}$ & & VR & $\mathbf{T}$ & & VR & $\mathbf{T}$ & \\
\hline $\begin{array}{l}\text { (a) How engaging was the content delivery } \\
\text { method? }\end{array}$ & 4.8 & 3.4 & 1.4 & 6.9 & 5.7 & 1.2 & 5.9 & 4.5 & 1.4 \\
\hline $\begin{array}{l}\text { (b) How well do you think the copper processing } \\
\text { flowsheet was explained to you? }\end{array}$ & 4.4 & 3.5 & 0.9 & 6.3 & 5.0 & 1.3 & 5.4 & 4.3 & 1.1 \\
\hline $\begin{array}{l}\text { (c) How enjoyable did you find the experience of } \\
\text { learning about the copper processing flowsheet? }\end{array}$ & 4.9 & 3.9 & 1.0 & 6.7 & 5.1 & 1.6 & 5.8 & 4.5 & 1.3 \\
\hline $\begin{array}{l}\text { (d) How interested are you in learning about more } \\
\text { processing flowsheets? }\end{array}$ & 5.6 & 3.5 & 2.1 & 6.7 & 5.6 & 1.1 & 6.2 & 4.6 & 1.6 \\
\hline $\begin{array}{l}\text { (e) How easy did you find it to understand the } \\
\text { material used to explain the copper processing } \\
\text { flowsheet? }\end{array}$ & 5.0 & 3.3 & 1.7 & 5.7 & 4.0 & 1.7 & 5.4 & 3.7 & 1.7 \\
\hline
\end{tabular}

Students were asked five open-ended questions where they were required to explain the operation of a particular equipment or understanding of a concept. A zero-to-one point rubric was created to score responses consistently. In scoring, the use of appropriately labelled diagrams and drawings that were part of the correct answer were accepted even when the question did not specifically request their use. One point was given when the student response was reasonably correct, and satisfactory, 0.5 point was given when the student response had minor omissions and/or some incorrect or irrelevant information, and 0 point was given when the student attempted the task, but the response was 
incorrect or inappropriate. The questions and the survey results are given in Table 4. Overall, the undergraduate students who took the VR delivery mode performed better than those taking the traditional or in-class teaching mode in answering the knowledge questions correctly. In all five questions asked, the undergraduate VR respondents gave better responses than the in-class respondents while the postgraduate VR respondents gave better responses to three of the five knowledge questions.

Table 4 Results of post-test knowledge of open-ended questions from both surveys study groups

\begin{tabular}{|c|c|c|c|c|c|c|}
\hline \multirow{3}{*}{ Statement } & \multicolumn{3}{|c|}{ Undergraduate } & \multicolumn{2}{|c|}{ Postgraduate } & \multirow{3}{*}{ Diff. } \\
\hline & \multicolumn{2}{|c|}{$\%$} & \multirow[t]{2}{*}{ Diff. } & \multicolumn{2}{|c|}{$\%$} & \\
\hline & $\mathbf{V R}$ & $\mathbf{T}$ & & VR & $\mathbf{T}$ & \\
\hline (a) The grinding circuit consists of.... & 66.7 & 37.5 & 29.2 & 57.1 & 28.6 & 28.5 \\
\hline (b) Explain the role of the cone crusher in the grinding circuit. & 38.9 & 6.3 & 32.6 & 21.4 & 35.6 & -14.2 \\
\hline (c) Name each stage in the flotation circuit. & 38.9 & 31.3 & 7.6 & 100 & 85.7 & 14.3 \\
\hline (d) Explain why flotation takes place in multiple stages. & 72.2 & 50 & 22.2 & 71.4 & 64.3 & 7.1 \\
\hline (e) Which of the following statements are correct? & 38.9 & 37.5 & 1.4 & 57.1 & 64.3 & -7.2 \\
\hline
\end{tabular}

\section{Conclusion}

An interactive base metal concentrator module has recently been developed at UNSW Sydney to bring a virtual mineral processing plant to the university environment, where students can experience a real plant and visualise unit operations in 3D. The virtual reality module has actively been integrated into teaching to enhance student engagement and learning. A survey was conducted to compare two different teaching delivery modes and assess their impact on students' learning outcomes.

The survey results showed that the majority of students preferred VR over the traditional method, with a higher proportion of postgraduate students preferring the VR delivery mode than undergraduate students. Comments from the students indicated that the VR mode provided a simulated and engaging environment due to its interactive nature. While VR was the preferred method by both groups of students, some students preferred the traditional, in-class teaching. This suggests that the VR mode should not replace face-to-face teaching completely but instead it can provide students with a valuable alternative educational media to convey engineering knowledge on processing plant operation.

Face-to-face courses are increasingly incorporating some alternative teaching strategies such as online components, and blended learning where traditional in-class activities are supplemented to improve student engagement and learning outcomes. The survey results suggest that the use of VR technology may be another option for complementing and supporting traditional teaching.

\section{References}

Ata, S., 2017. Interactive visualization of a base-metal concentrator. CIM Journal, 8(3).

Bell, J.T. and H.S. Fogler, 1995. The investigation and application of virtual reality as an educational tool. Proceedings of the American Society for Engineering
Education 1995 Annual Conference (ASEE), June, Anaheim, CA, 2: 1718 - 1728.

Bell, J.T. and H.S. Fogler, 1996. Recent developments in virtual reality based education. Proceedings of the American Society for Engineering Education Annual Conference, June 23 - 26, Washington, DC, pp2669 2674

Bell, J.T. and H.S. Fogler, 1998. Virtual reality in chemical engineering education. Proceedings of the 1998 American Society for Engineering Education ASEE North Central Section Meeting, April 3 - 4, Detroit, MI.

Hsu, K.S., 2011. Application of a virtual reality entertainment system with human-machine sensor device. Journal of Applied Sciences, 11(12): 2145 2153.

Jiang, M., 2011. Virtual reality boosting automotive development. In D. Ma, X. Fan, J. Gausemeier and M. Grafe (Eds.), Virtual reality \& augmented reality in industry. Berlin, Heidelberg: Springer, pp171 - 180.

Laurence, D. and P. Stothard, 2010. Applications of simulation methodologies for a sustainable mining industry. Proceedings of Advanced Mining for Sustainable Development, Ha Long Bay, Vietnam, pp50 - 59.

Manojlovich, J., P. Prasithsangaree, S. Hughes, J. Chen and M. Lewis, 2003. UTSAF: A multi-agent-based framework for supporting military-based distributed interactive simulations in 3-D virtual environments. Proceedings of the Winter Simulation Conference, New Orleans, LA, USA, 1: 960 - 968.

Mitra, R. and S. Saydam, 2011. Using virtual reality for improving health and safety of mine workers and improving mining engineering education in Australia. Proceedings of the 34th International Conference of Safety in Mines, New Delhi, India, pp625 - 636.

Saydam, S., R. Mitra and C. Russell, 2011. A four dimensional interactive learning system approach to 
mining engineering education. Proceedings of the Second International Future Mining Conference. In S. Saydam (Ed.), Proceedings of the Second International Future Mining Conference, Sydney, Australia, NSW, pp279 - 286.

Schofield, D., E. Lester and J.A. Wilson, 2005. Virtual reality based, interactive e-learning for chemical engineers. Proceedings of the Seventh World Congress of Chemical Engineering, Rugby, UK, Institution of Chemical Engineers.

Shin, Y.S., 2002. Virtual reality simulations in web-based science education. Computer Applications in Engineering Education, 10(1): 18 - 25.
Squelch, A.P., 2001. Virtual reality for mine safety training in South Africa. The Journal of The South African Institute of Mining and Metallurgy, 101(4): 209 - 216.

Squires, R.G., P.K. Andersen, G.V. Reklaitis, S. Jayakumar and D.S. Carmichael, 2015. Multimedia-based educational applications of computer simulations of chemical engineering processes. Computer Applications in Engineering Education, 1(1): 25 - 32.

Zimmermann, P., 2008. Virtual reality aided design. A survey of the use of VR in automotive industry. In D. Talaba and A. Amditis (Eds.), Product engineering, Springer, Netherlands, pp277 - 296

\section{Appendix - The five close-ended questions}

\begin{tabular}{|c|c|c|c|c|c|c|}
\hline \multicolumn{7}{|c|}{ (a) How engaging was the content delivery method? } \\
\hline $\begin{array}{l}\text { Extremely } \\
\text { boring }\end{array}$ & Very boring & Slightly boring & Engaging & $\begin{array}{l}\text { Moderately } \\
\text { engaging }\end{array}$ & $\begin{array}{l}\text { Highly } \\
\text { engaging }\end{array}$ & $\begin{array}{l}\text { Extremely } \\
\text { engaging }\end{array}$ \\
\hline \multicolumn{7}{|c|}{ (b) How well do you think the copper processing flowsheet was explained to you? } \\
\hline $\begin{array}{l}\text { Extremely } \\
\text { poorly }\end{array}$ & Really poorly & Pretty poorly & Okay & Pretty well & Really well & Extremely well \\
\hline \multicolumn{7}{|c|}{ (c) How enjoyable did you find the experience of learning about the copper processing flowsheet? } \\
\hline $\begin{array}{l}\text { Extremely } \\
\text { boring }\end{array}$ & Very boring & Slightly boring & Okay & $\begin{array}{l}\text { Moderately } \\
\text { enjoyable }\end{array}$ & $\begin{array}{l}\text { Highly } \\
\text { enjoyable }\end{array}$ & $\begin{array}{l}\text { Extremely } \\
\text { enjoyable }\end{array}$ \\
\hline \multicolumn{7}{|c|}{ (d) How interested are you in learning more about processing flowsheets? } \\
\hline \multicolumn{7}{|c|}{ (e) How easy did you find it to understand the material used to explain the copper processing flowsheet? } \\
\hline $\begin{array}{l}\text { Extremely } \\
\text { difficult }\end{array}$ & Very difficult & $\begin{array}{l}\text { Slightly } \\
\text { difficult }\end{array}$ & Okay & Pretty easy & Very easy & Extremely easy \\
\hline
\end{tabular}

